\title{
Análise de aspectos sociocientíficos em livros didáticos de química para a primeira série do ensino médio
}

\author{
João Paulo Stadler*, Mariana da Silva Azevedo**
}

\section{Resumo}

Investigar possibilidades para o uso do livro didático é relevante devido à importância desse recurso didático, ao ponto de se tornar o único instrumento de estudo para o aluno e de apoio ao professor, em razão da ampla distribuição promovida pelo Programa Nacional do Livro Didático (PNLD) no país. Dentre as várias concepções de ensino de Química, a abordagem de Aspectos Sociocientíficos (ASC) utiliza a contextualização com base em temas socialmente relevantes mobilizados pela discussão de controvérsias pautada no conhecimento científico. Por isso, investigar a presença de ASC nos livros didáticos de Química pode auxiliar os professores a empregar essa concepção de ensino. Esta pesquisa foi centrada na análise dos livros de Química destinados à primeira série do Ensino Médio pelo PNLD. A metodologia empregada foi a análise de conteúdo baseadas nos indicadores: tema global, presença de controvérsia e critérios de relevância para classificar os textos em potenciais promotores de discussões sociocientíficas. Posteriormente foi delimitado o tipo de abordagem e o tipo de controvérsia apresentados. Verificou-se que as grandes diferenças entre as obras impedem sua comparação por fragmento. Dessa forma, optou-se por fragmentá-las na categorização, produzir um perfil para as obras e, a partir dele, compará-las. Embora todas as obras tenham apresentado fragmentos com potencial de fomentar a discussão sociocientífica, os livros não trazem todas as informações necessárias para a discussão controvertida. Além disso, constatou-se a necessidade de aumentar a quantidade de temas de contexto e tipos de abordagem para abarcar os exemplos contidos nos livros.

Palavras-Chave: Aspectos sociocientíficos; Livro didático; PNLD; Ensino de Química.

\footnotetext{
- Mestre e doutorando em Ensino de Ciências e Matemática pelo Programa de Pós-Graduação em Formação Científica, Educacional e Tecnológica da Universidade Tecnológica Federal do Paraná - campus Curitiba. Professor do Colegiado de Química do Instituto Federal de Educação, Ciência e Tecnologia do Paraná - campus Palmas. Brasil. E-mail: joao.stadler@ifpr.edu.br.

* Doutora em Ciências pelo Centro de Energia Nuclear na Agricultura da Universidade de São Paulo. Professora do Colegiado de Ciências Biológicas do Instituto Federal de Educação, Ciência e Tecnologia do Paraná - campus Palmas. Brasil. E-mail: mariana.azevedo@ifpr.edu.br
} 


\section{Introdução}

A Lei de Diretrizes e Bases da Educação (BRASIL, 1996) e, mais especificamente a Base Nacional Comum Curricular (BRASIL, 2017), estabelecem que o ensino de Química, dentro da área de Ciências da Natureza, deve fomentar a construção de conhecimentos contextualizada e a preparação dos estudantes para a argumentação, a tomada de decisão e a proposição de alternativas frente a temas contextualizados.

Para conseguir atingir esses objetivos, a abordagem de aspectos sociocientíficos (ASC) pode ser uma metodologia adequada por tratar esses assuntos visando a argumentação e a tomada de decisão (SANTOS; MORTIMER, 2001). Essa metodologia é pautada, então, na elaboração e interpretação de argumentos acerca de uma controvérsia que relacione os vários contextos a serem estudados, sem o detrimento do conteúdo científico (PÉREZ; CARVALHO, 2012). Entretanto, ambos os trabalhos apontam que os pontos positivos verificados no emprego de ASC em sala de aula foram a maior participação dos alunos nas aulas e, em consequência, o desenvolvimento de habilidades e competências concernentes aos discursos, entre eles a falta de segurança do professor em tratar sobre controvérsias em sala de aula, a dificuldade dos alunos em entenderem os processos argumentativos, o conflito com as ideias tradicionais do ensino e o problema com os livros didáticos.

A dependência dos professores em relação ao livro didático e a sequência determinada em seus índices foi abordada na tese de doutorado de Fracalanza (1992), mas ainda é recorrente, sendo apontada por Delizoicov, Angotti e Pernambuco (2018). As justificativas para tal dependência são variadas, entre elas a baixa qualificação dos professores e as diferentes clientelas que passaram a frequentar a escola (FRACALANZA, 1992), ou seja, ou livros didáticos servem como um parâmetro nivelador dos conteúdos planejados e das atividades abordadas. O problema em relação à dependência dos professores com o livro didático, além da questão da fragmentação que é gerada, alicerça-se nas deficiências desses materiais que, em 1992 eram, entre outras, a excessiva preocupação com a memorização de fórmulas e a utilização dos experimentos como prova de teoria (FRACALANZA, 1992). Atualmente, apesar da existência de diretrizes para a organização dos livros didáticos, Neto e Fracalanza (2003) afirmam que os materiais destoam muito das recomendações legais.

Outro ponto importante a ser considerado em relação ao livro didático é a grande abrangência conferida a eles pelo Programa Nacional do Livro Didático (PNLD) 
que tem por objetivo distribuir de maneira universal de livros didáticos aprovados aos alunos da Educação Básica em períodos específicos (ciclos trienais alternados entre Ensino Fundamental e Ensino Médio), de modo a atender os preceitos de cidadania estipulados pala Constituição em relação à qualidade e universalidade do ensino (BRASIL, 2017). Esse fato faz com que o livro didático seja o único contato da parcela mais carente da população com os conteúdos científicos, devido a falta de outras políticas que assegurem o acesso de materiais didáticos diversificados.

Considerando esses fatores, fica indicada a necessidade de verificar como os livros didáticos de Química abordam essa metodologia, de modo a indicar para os professores como utilizar as obras de acordo com seus objetivos de trabalho. Desta forma, objetiva-se apresentar uma descrição das obras aprovadas pelo PNLD por meio da análise de conteúdo das obras para categorizá-las e verificar a ocorrência, o tipo de abordagem e o tipo de controvérsia presentes. Acredita-se que desta forma, pode-se indicar o emprego de ASC na Educação Básica.

\section{As características dos aspectos sociocientíficos em materiais de larga escala}

De acordo com Santos (2002), são critérios para a abordagem sociocientífica: $a$ controvérsia, ou seja, o conflito entre opiniões expressas sobre o tema; o significado social, isto é, se o tema apresenta relevância para a comunidade na qual será discutido; e a relação com a ciência ou tecnologia, a qual comportaria com conteúdo a ser discutido. Perez e Carvalho (2012) também salientam a importância da ligação entre o tema a ser abordado e a realidade dos alunos, para que esses possam emitir suas opiniões e fundamentar suas decisões em suas vivências, embora seja necessária atenção para que esses valores e o desenvolvimento de habilidades e competências não ofusquem a importância da aquisição com conhecimento científico nas aulas de ciências.

A abordagem desses aspectos durante o processo de ensino e aprendizagem deve ser feita de modo a promover a discussão dos alunos entorno de uma controvérsia acerca de um tema escolhido, ou ainda, a relação entre os aspectos e os conteúdos científicos podem suscitar temas que atuarão como geradores para a discussão. Em ambos os casos, o emprego de ASC visa a ressignificação dos conteúdos tornando-os mais próximos dos alunos (SANTOS; MORTIMER, 2009). 
Tendo em vista o caráter de larga escala do PNLD, faz-se necessários que os elementos de contextualização presentes nas obras sejam reconhecidos como importantes pela população em geral. Nesse sentido, nos apropriamos dos temas globais apresentados por Merryfield (1991 apud SANTOS 2002) como temas de significância social em exames de larga escala. Para Merryfield, existem problemas regionais e globais que podem ser utilizados como fonte de controvérsia para discutir ASC, sendo eles: temas ambientais; saúde e população; questões econômicas; transporte e comunicação; alimentos e fome; energia e questões militares, por serem assuntos frequentemente divulgados na mídia e que são de interesse da maioria da população.

Em trabalho mais atual, Fernandes-Sobrinho (2014) apresentou uma série de critérios que indicam se um assunto apresente relevância social para uma discussão sociocientífica. Esses elementos conferem à abordagem a relevância social necessária para que as pessoas se engajem em discuti-las. São eles: ter base na ciência, frequentemente em áreas que estão nas fronteiras do conhecimento científico; envolver a formação de opiniões e a realização de escolhas no nível pessoal e social; ser frequentemente divulgadas pela mídia com destaque a aspectos baseados nos interesses dos meios de comunicação; lidar com informação incompleta sejam elas de evidências científicas incompletas ou conflitantes e lacunas nos registros; lidar com problemas locais e globais e suas estruturas sociais e políticas; envolver a análise de custo e benefício na qual os riscos interagem com valores; envolver considerações sobre desenvolvimento sustentável; envolver valores e raciocínio ético; requerer algum entendimento de probabilidade e risco; e ser frequentemente pontuais durante a transição de uma vida.

Quando tratamos de abordagem de conteúdos, é interessante entender como essa abordagem é realizada em função da maneira como é inserida na prática docente e conduzida durante o processo de ensino e aprendizagem. Nesse sentido, Santos (2002) e Halmenschlager e Delizoicov (2017) apresentam os tipos de abordagem na concepção e construção de uma prática pedagógica que possibilite a formação do cidadão, que pode ser feita de três modos que podem ser complementares: de forma temática, quando se emprega um assunto geral para suscitar as discussões fomentadas pelo conhecimento científico; de forma pontual, quando os conceitos estudados estão intimamente ligados a um fato ou fenômeno cotidiano específico; e descritos de forma concomitante ao conteúdo, por meio de questionamentos dirigidos acerca do tema. 
Existem várias maneiras de se promover cada uma dessas formas, de acordo com as possibilidades e objetivos do professor, mas independentemente da forma de abordagem de ASC no processo de ensino e aprendizagem, o que deve ocorrer é o estímulo a um processo de discussão centrado em uma controvérsia. O professor pode buscar temas controversos a partir do tema (contexto social) ou do conteúdo escolar, caso não apareçam naturalmente nas discussões em sala de aula. Em ambos os casos, o emprego de ASC prevê a ressignificação dos conteúdos, tornando-os mais próximos à realidade vivida pelos estudantes (SANTOS; MORTIMER, 2009).

Por fim, outro aspecto interessante sobre a abordagem de ASC é o tipo de controvérsia apresentada, no que diz respeito a como a discussão entorno da controvérsia é apresentada aos estudantes nas atividades. Em relação a essa classificação, Stadler (2015) identificou em exame de larga escala a presença de dois tipos de controvérsia: a tomada de decisão, quando a questão controvertida requer que o estudante escolha a melhor alternativa para a solução de um problema ou tome partido frente a explicações controversas sobre o mesmo tema, por exemplo; e a justificativa de escolha / decisão, quando a tarefa consiste em argumentar sobre assuntos controversos que justifiquem ou critiquem uma decisão ou escolha feita por outrem.

\section{Encaminhamentos metodológicos}

Esta pesquisa se configura como uma análise bibliográfica de caráter qualitativo (GIL, 2010), baseada na análise de conteúdo (BARDIN, 2011), na qual são realizadas três etapas: pré-análise, que consiste na escolha do corpus e da elaboração dos indicadores de análise; análise, na qual a técnica é aplicado ao corpus; e na síntese dos resultados, na inferência e na interpretação.

A etapa de pré-análise, que denominamos de análise preliminar das obras, consistiu no contato inicial com os livros para estabelecer como se daria a comparação entre os elementos do corpus que foram analisados. Nessa fase é realizada a leitura superficial (dinâmica) do livro completo a fim de identificar como a obra é dividida e, finalmente, como as obras poderiam ser comparadas em função dessa divisão. Além disso, nesta primeira etapa, foram elencados os indicadores da análise: 
a) corpus: os livros didáticos de Química disponibilizados pelo PNLD 2018, destinados à primeira série do Ensino Médio:

i. Livro 1: Química (REIS, 2016);

ii. Livro 2: Química (MORTIMER; MACHADO, 2017);

iii. Livro 3: Química Cidadã (SANTOS; MÓL, 2016);

iv. Livro 4: Ser Protagonista - Química (LISBOA, 2016);

v. Livro 5: Química (CISCATO et al., 2016);

vi. Livro 6: Vivá - Química (NOVAIS; ANTUNES, 2016).

b) unidade de registro: palavra;

c) regra de enumeração: presença;

d) critério de categorização: semântico;

e) indicadores: controvérsia, temas globais, conteúdo científico e critérios de relevância social de abordagem sociocientífica, sendo:

i. Controvérsia: o fragmento de texto deve trazer elementos que permitam a discussão de dois pontos de vista conflitantes para a resolução de um problema;

ii. Temas globais: Merryfield apresentou como indicadores de relevância social em documentos de grande escala os seguintes elementos: temas ambientais; saúde e população; questões econômicas; transporte e comunicação; alimentos e fome; energia; e questões militares (1991 apud SANTOS, 2002). Esses temas seriam, em tese, de conhecimento de todos os cidadãos em razão de sua importância para a vida.

iii. Conteúdo científico: este indicador é citado como elemento essencial para a abordagem de ASC, mas considera-se aqui que estão sempre presentes, uma vez que as obras são livros didáticos.

iv. Critérios de relevância social de abordagem sociocientífica: apresentados por Fernandes-Sobrinho (2014), esses elementos conferem à abordagem a relevância social necessária para que as pessoas se engajem em discuti-las. São eles: 1) ter base na ciência, frequentemente em áreas que estão nas fronteiras do conhecimento científico; 2) envolver a formação de opiniões e a realização de escolhas no nível pessoal e social; 3) ser frequentemente divulgadas pela mídia com destaque a aspectos baseados nos interesses dos meios de comunicação; 4) lidar com informação incompleta sejam elas de 
evidências científicas incompletas ou conflitantes e lacunas nos registros; 5) lidar com problemas locais e globais e suas estruturas sociais e políticas; 6 ) envolver a análise de custo e benefício, na qual os riscos interagem com valores; 7) envolver considerações sobre desenvolvimento sustentável; 8) envolver valores e raciocínio ético; 9) requerer algum entendimento de probabilidade e risco; e 10) ser frequentemente pontuais durante a transição de uma vida.

f) categorias: com potencial para abordagem de ASC ou sem potencial para abordagem de ASC.

No segundo momento, que aqui chamamos de análise aprofundada das obras, as divisões estabelecidas na etapa anterior são lidas com profundidade a fim de realizar a categorização com base nos indicadores apresentados acima. É feito o registro da análise com uma rápida descrição de cada fragmento, seguida da identificação da presença dos elementos necessários para classificá-las quanto à abordagem de ASC. Nesta etapa, cada fragmento do livro foi incluído em tabela de análise (que, por questões de espaço foram anexadas como material complementar). Foram, então, classificados como fragmentos com potencial para a abordagem de ASC aqueles que apresentam: relação com um dos temas globais; uma controvérsia; e ao menos um dos critérios de relevância social de abordagem sociocientífica.

A terceira etapa consistiu, então, na construção dos resultados de análise e são apresentadas no próximo item deste artigo. É importante salientar que a análise de conteúdo, mesmo contando com os critérios de caracterização das categorias, depende da interpretação do analista frente aos fragmentos do corpus analisado. Em razão disso, serão apresentados os motivos que levaram à classificação proposta após as tabelas de apresentação dos resultados da categorização. Quanto às tabelas de categorização, elas são, em analogia, como o caderno de campo ou de laboratório, ou seja, servem de anotação para as observações da pesquisa. Por isso, para a compreensão da análise de modo integral, é interessante combinar a tabela de análise (material complementar) e as sínteses aqui apresentadas.

Ainda, além da categorização com os indicadores propostos, este estudo atribuiu mais duas características àqueles fragmentos que foram classificados com potencial para abordagem de ASC. São eles: o tipo de abordagem (pontual; temática; ou por questionamento), de acordo com o apresentado por Santos (2002); e o tipo de controvérsia (justificativa de escolha ou tomada de decisão), trazido em Stadler 
(2015). O objetivo desse movimento foi trazer mais elementos para a caracterização de possíveis práticas sociocientíficas em sala de aula.

\section{Resultados e discussões}

É importante esclarecer que a classificação demanda a construção de uma tabela descritiva de todos os recortes das obras, o que acaba por produzir documentos bastante extensos. Por isso, os resultados serão apresentados de maneira sucinta, com o detalhamento de apenas alguns exemplos, por questão de espaço.

\section{Resultado da análise preliminar}

Essa etapa teve por objetivo identificar possíveis recortes nas obras do corpus para que a categorização possa ser feita em partes para, ao final, caracterizar a obra por completo. Sendo assim, são apresentadas, no quadro 1, as características principais das seis obras estudas:

Quadro 1: Organização do conteúdo das obras analisadas

\begin{tabular}{|c|l|l|l|}
\hline Obras & \multicolumn{1}{|c|}{ Estrutura de divisão do conteúdo } & $\begin{array}{c}\text { Quantidade } \\
\text { de Unidades }\end{array}$ & $\begin{array}{l}\text { Quantidade } \\
\text { de Capítulos }\end{array}$ \\
\hline Livro 1 & $\begin{array}{l}\text { O conteúdo é dividido em unidades temáticas acerca da } \\
\text { poluição. As unidades são divididas em capítulos de acor- } \\
\text { do com conteúdo químico }\end{array}$ & 11 \\
\hline Livro 2 & $\begin{array}{l}\text { O conteúdo é dividido em capítulos de acordo com o con- } \\
\text { teúdo químico }\end{array}$ & - & 9 \\
\hline Livro 3 & $\begin{array}{l}\text { O conteúdo é dividido em capítulos de acordo com o con- } \\
\text { teúdo químico }\end{array}$ & - & 7 \\
\hline Livro 4 & $\begin{array}{l}\text { O conteúdo é dividido em unidades e essas em capítulos } \\
\text { de acordo com conteúdo químico }\end{array}$ & 4 & 14 \\
\hline Livro 5 & $\begin{array}{l}\text { O conteúdo é organizado em capítulos de acordo com a } \\
\text { aplicação prática (na maioria dos casos). Os capítulos são } \\
\text { divididos em temas de acordo com o conteúdo químico }\end{array}$ & 6 & 23 \\
\hline Livro 6 & $\begin{array}{l}\text { O conteúdo é dividido em unidades e essas em capítulos } \\
\text { de acordo com conteúdo químico }\end{array}$ & 4 & 12 \\
\hline
\end{tabular}

Fonte: autoria própria, a partir das obras do corpus (REIS, 2016; MORTIMER; MACHADO, 2017; SANTOS; MÓL, 2016; LISBOA, 2016; CISCATO et al., 2016; NOVAIS; ANTUNES, 2016) 
A partir dos dados apresentado no quadro 1, é possível perceber que as obras não possuem estritamente a mesma organização. Mesmo os livros que apresentam a mesma estrutura (livros 2 e 3) ou estruturas similares (livros 1, 4 e 6) contêm quantidades diferentes de unidades e capítulos. O livro 5, apesar de apresentar "capítulos" e "temas" como divisões, pode ser comparado àqueles que trazem "unidades" e "capítulos", embora apresente o conteúdo mais fragmentado nas suas divisões. O livro 1, em contraste com os demais, apresenta o interessante aspecto de dividir as unidades em razão de problemas ambientais, que apresentam relação com os temas ambientais propostos por Merryfield (1991, apud SANTOS, 2002).

Diante das diferenças de organização observadas, optou-se por realizar a comparação das obras como um todo, ao invés de compará-las por fragmentos. Contudo, para facilitar a leitura da obra e sua categorização, as unidades do livro foram divididas em partes, tratadas aqui como seções: seção de abertura - parte introdutória do capítulo que tem por finalidade a apresentação do que será abordado; seção de conteúdo - fragmento que apresenta o conteúdo químico a ser trabalhado; e seção de encerramento: recorte final que pode aparecer com o intuito de sumarizar o que foi trabalhado. Segundo esse critério de recorde, é feita a descrição preliminar das obras.

O livro 1 (REIS, 2016) apresenta uma seção de abertura, mas não contém uma seção de encerramento. Dentro das unidades, cada capítulo conta com sua própria seção de abertura com uma notícia divulgada em jornais e, ao final, é feita a recapitulação do assunto tratado na abertura estabelecendo relações com o conteúdo abordado no capítulo, figurando como seção de encerramento. A seção de conteúdo contém diversos boxes com finalidades específicas que aparecem randomicamente e os exercícios são todos agrupados em uma seção própria. Em função do exposto, essa foi fragmentada em: seção de abertura da unidade; seção de abertura do capítulo; seção de conteúdo e seção de encerramento do capítulo.

É possível perceber que o livro 2 (MORTIMER; MACHADO, 2017) apresenta uma seção de abertura nos capítulos, que traz um pequeno texto autoral e perguntas para iniciar o conteúdo, mas não apresenta seção de encerramento. A obra também mostra organização diferenciada das demais, pois contém mais boxes ao longo dos capítulos, de modo que os textos de conteúdo são mais curtos. Essa obra foi fragmentada em: seção de abertura do capítulo e seção de conteúdo.

Observa-se que no livro 3 (SANTOS; MÓL, 2016), cada capítulo é organizando contendo uma seção de abertura, com uma imagem e um pequeno texto descritivo 
autoral sobre o que será estudado na unidade. A seção de encerramento é composta por exercícios discursivos e de múltipla escola, mas há ocorrência de exercícios no meio do capítulo. A obra, então é fragmentada em seção de abertura, seção de conteúdo e seção de encerramento do capítulo.

O livro 4 (LISBOA, 2016) apresenta unidades com seção de abertura que estimulam discussão de conhecimentos prévios. Não foi encontrada, em contrapartida, uma seção de encerramento da unidade. Cada capítulo, por sua vez, contém uma seção de abertura própria, com imagem e um texto de introdução e uma seção de encerramento que, além de apresentar um box para questões finais, mostra elementos que variam caso a caso. Por essa questão, a seção de encerramento de cada capítulo para essa obra será dividida. Sendo assim, esse livro foi dividido em: seção de abertura da unidade; seção de abertura do capítulo; seção de conteúdo e seção de encerramento do capítulo (subdividida).

livro 5 (CISCATO et al., 2016), por sua vez, apresenta estrutura bastante singular quando comparado com as outras obras, pois traz capítulos divididos em temas, em contraste a unidades e capítulos. Os temas são bastante específicos e, por isso, curtos. Ocorrendo casos de temas sem boxes, por exemplo. Além disso, os capítulos apresentam seção de abertura e de encerramento subdivididas. No primeiro caso, há apresentação de uma imagem e um texto de contextualização do tema, de questões de reflexão sobre a imagem e o texto especificamente e, ainda, questões para antecipação do conteúdo, com exploração de conhecimentos prévios. Em semelhança, a seção de encerramento do capítulo também é subdividida em exercícios finais, com questões alternativas e discursivas, e uma proposta de trabalho em grupo. Os temas, subdivisões internas dos capítulos, não apresentam seção de abertura, mas apresentam seção de encerramento com exercícios.

Outras singularidades dessa obra referem-se ao box genérico que tem diversas denominações (por isso foram agrupados) e visam promover a multidisciplinaridade e ao glossário que, como visa apenas definir palavras, não poderia abarcar todas as características requeridas para a abordagem de ASC, não sendo descritos na análise aprofundada. Sendo assim, a obra foi fragmentada em: seção de abertura do capítulo (subdividida), seção de conteúdo do tema, seção de encerramento do tema e seção de encerramento do capítulo. É importante sempre atentar-se para a relação entre os capítulos dessa obra com as unidades das demais (que possuem) e dos temas com os capítulos. 
Finalmente, o livro 6 (NOVAIS; ANTUNES, 2016) apresenta unidades com seção de abertura e encerramento bem delineadas. A primeira apresenta manchetes para contextualização do tema que será abordado e a segunda, exercícios sobre o tema. Cada capítulo também apresenta seções de abertura, com questionamentos que visam a discussão de conhecimentos prévios, e de encerramento, com exercícios. Dessa forma, essa obra foi fragmentada em seção de abertura da unidade; seção de abertura do capítulo; seção de conteúdo, seção de encerramento do capítulo e seção se encerramento da unidade.

Tendo em vista as diferenças na divisão prevista para as obras acima, é apresentado o quadro 2 para assinalar de maneira clara quais as divisões de cada obra.

Quadro 2: Divisão das obras para categorização

\begin{tabular}{|c|c|c|c|c|c|c|}
\hline Divisões & Livro 1 & Livro 2 & Livro 3 & Livro 4 & Livro $5^{c}$ & Livro 6 \\
\hline Seção de abertura da unidade & $x$ & $-{ }^{a}$ & $-{ }^{a}$ & $X^{b}$ & $x$ & $x$ \\
\hline Seção de abertura do capítulo & $x$ & $x$ & $\mathrm{X}$ & $x$ & -- & $x$ \\
\hline Seção de conteúdo b & $x$ & $x$ & $x$ & $x$ & $x$ & $x$ \\
\hline Seção de encerramento do capítulo & $x$ & -- & $\mathrm{X}$ & $x$ & $X^{b}$ & $\mathrm{x}$ \\
\hline Seção de encerramento da unidade & -- & - a $^{2}$ & - a $^{a}$ & -- & $X^{b}$ & $x$ \\
\hline
\end{tabular}

Legenda: a: obra sem presença de unidades.

b: seção subdivida.

c: nessa obra as unidades são denominadas capítulos e os capítulos, temas.

Fonte: autoria própria, a partir das obras do corpus (REIS, 2016; MORTIMER; MACHADO, 2017; SANTOS; MÓL, 2016; LISBOA, 2016; CISCATO et al., 2016; NOVAIS; ANTUNES, 2016)

A partir da observação do quadro 2 é possível perceber que a organização interna das obras, que culminaram na divisão estabelecida, é bastante particular de cada obra. Além da organização em capítulos/unidades e unidades/temas apresentada no quadro 1, percebe-se que, em alguns casos, há necessidade de subdivisões nas seções de encerramento dos capítulos e unidades.

Em relação à seção de conteúdo, é importante notar a presença de diversos boxes, destacados do texto de conteúdo, cuja função é complementar as informações apresentadas sobre o tema por meio de contextualização ou interdisciplinaridade e exercícios. A partir da análise preliminar dos livros, observou-se que cada obra é composta por um conjunto muito particular de boxes, que serão apresentados na análise aprofundada, como subdivisões da seção de conteúdo. 
Dessa forma, decidiu-se por categorizar cada fragmento e a partir deles caracterizar a obra como um todo. Somente após a análise aprofundada das obras procedeu-se com a comparação entre os livros. É importante salientar que a quantidade de fragmentos de cada obra é diferente, em razão da presença/ausência dos elementos principais e, também, em razão das subdivisões em alguns deles. A seção de conteúdo é a mais particular nesse exemplo, onde cada box foi considerado como uma subdivisão e analisado (com exceções do box glossário do livro 5).

\section{Resultado da análise aprofundada}

Nessa etapa foi feita, em cada divisão/subdivisões das obras (quadro 2), a busca dos indicadores empregados para caracterizar a potencialidade de abordagem de ASC. Nas tabelas de classificação é feita uma breve descrição do fragmento (com a indicação de página das ocorrências principais) acompanhada da descrição do tema global (SANTOS, 2002), da controversa, com a tipificação (STADLER, 2015), o critério de relevância social de abordagem sociocientífica (SOBRINHO-FERNANDES, 2014), a tipificação da abordagem, caso contenha todos os elementos precedentes (SANTOS, 2002; HALMENSCHLAGER; DELIZOICOV, 2017) e, se necessário, comentários dos analistas. É importante salientar que a tipificação da abordagem não é um indicador, mas é um dado importante para a inferência sobre como as atividades com potencialidades para a abordagem de ASC poderiam ser trabalhadas em sala de aula.

Em relação aos temas globais de Merryfield (1991, apud SANTOS, 2002), sua escolha refere-se ao fato de que as obras promovidas pelo PNLD, assim como os exames de larga escala (nos quais os temas foram estudados) são destinados a uma população muito heterogênea, de modo que é necessário buscar elementos de relevância social que sejam o mais abrangentes possível. A questão da relevância é corroborada pelos critérios de relevância social na abordagem sociocientífica (FERNANDES-SOBRINHO, 2014), que são empregados na caracterização da controvérsia em temos de relevância social. Em relação ao critério lidar com problemas locais e globais e suas estruturas sociais e políticas, considerou-se que os problemas locais referiam a problemas com impacto em certa região (não sendo necessariamente a região de residência dos consumidores da obra) e problemas globais eram relacionados a problemas reconhecidos em escala global. 
Para realizar a tipificação da controvérsia em tomada de decisão ou avaliação/ justificativa de escolha foram considerados que no primeiro caso, deve-se escolher entre alternativas possíveis para a solução de problemas ou escolher um lado de uma discussão para seguir, enquanto que no segundo caso, deve-se usar valores e análises de custo-benefício para avaliar ou justificar uma decisão tomada por outrem (STADLER, 2015).

A seguir serão caracterizadas, qualitativamente, todas as unidades de contexto de cada obra, de acordo com a sistematizado nos quadros do documento complementar. Na indicação das páginas é colocada a página inicial da unidade de contexto, que pode se estender por várias páginas.

\section{Livro 1: Reis (2016)}

O quadro 3 sumariza as principais características das seções do livro 1 frente aos critérios de categorização, baseado nos exemplos de fragmentos com características de ASC retirados do material:

- Página 8: na seção de abertura da unidade 1 é apresentado um texto que cita dois grupos de cientistas com opiniões contrárias sobre as causas do aquecimento global. Foi possível indicar a presença do tema global Temas Ambientais e a controvérsia é evidenciada com a pergunta: "Em quem devemos acreditar?" que envolve a discussão de valores e deverá, idealmente, ser baseada em conceitos científicos. Além disso, foi possível verificar que a controvérsia proposta possui base na ciência; é frequentemente divulgada pela mídia; lida com informações incompletas com conflito de evidências científicas; lida com problemas globais; pode envolver questões sobre desenvolvimento sustentável; envolve valores de raciocínio ético, no que se refere à em quem acreditar; e pode requerer conhecimento de probabilidade e risco. Diante de todos esses aspectos, entendeu-se que essa seção tem potencial de promover a abordagem de ASC de maneira temática, ao englobar os temas e conteúdos da unidade.

- Página 27: na seção de abertura do capítulo 2 (contido na unidade 1) é apresentado um texto jornalístico sobre o investimento da Sabesp, empresa de saneamento de São Paulo, para auxiliar na formação de chuva e a opinião contrária de um cientista da USP sobre a ineficiência do processo. $\mathrm{O}$ texto foi relacionado a Temas Ambientais e a controvérsia centra-se na 
avaliação de uma escolha (no caso a da Sabesp). Foi possível verificar a base científica na argumentação do cientista; a necessidade de formação de opinião para se posicionar quanto a escolha da companhia; a presença de um problema local; a necessidade de avaliação de custo benefício para avaliar a escolha; a necessidade de julgamento baseado em valores; e a necessidade de entendimento de probabilidades e risco. Diante de todos esses aspectos, entendeu-se que essa parte tem potencial de promover a abordagem de ASC de maneira pontual, corroborando com a temática da unidade, embora o texto em si não traga claramente uma pergunta.

- Página 42: no box "De onde vem... para onde vai?" (seção de conteúdo do capítulo 2 da unidade 1) é apresentada a produção de óxido de cálcio relacionando seus usos (pontos positivos) com a poluição causada e condições de trabalho degradantes nos locais de extração (pontos negativos) e é estimulado um trabalho em equipe no qual os alunos deverão justificar a escolha em continuar produzindo o óxido de cálcio frente aos pontos negativos. Dessa forma, a seção foi classificada como potencial promotora de discussão de ASC centrada na controvérsia entorno da justificativa da atividade. É possível relacionar a necessidade de formação de opinião para justificar a escolha; a relação com problemas locais; a necessidade de avaliação de custo-benefício; a possibilidade de articulação com o desenvolvimento sustentável; a mobilização de valores e raciocínio ético para a escolha; e o entendimento de probabilidade e risco. Diante de todos esses aspectos, entendeu-se que essa seção tem potencial de promover a abordagem de ASC de maneira pontual, corroborando com a temática da unidade. A unidade pode ser relacionada com Temas Ambientais e Questões Econômicas.

- Página 68: no box "Curiosidade" (seção de conteúdo do capítulo 3 da unidade 1) intitulado "Os céticos do aquecimento global”, são apresentados de maneira mais elaborada os pontos realizados na página 8 de acordo com uma entrevista com um climatologista da USP. Embora não haja uma questão controvertida para os alunos, foi decidido que essa unidade possibilita a abordagem de ASC por meio da tomada de decisão sobre qual lado escolher em relação à existência ou não do aquecimento global (Temas Ambientais). Além disso, foi possível verificar que a controvérsia proposta possui base na ciência; é frequentemente divulgada pela mídia; lida com informações 
incompletas com conflito de evidências científicas; lida com problemas globais; pode envolver questões sobre desenvolvimento sustentável; envolve valores de raciocínio ético, no que se refere a em quem acreditar; e pode requerer conhecimento de probabilidade e risco. Diante de todos esses aspectos, entendeu-se que essa seção tem potencial de promover a abordagem de ASC de maneira pontual.

- Página 71: na seção de encerramento da unidade 1 é mencionada, novamente, a controvérsia entre a causa antrópica ou não do aquecimento global (Temas Ambientais), como fechamento às questões de abertura. Novamente é posta a questão "Em quem devemos acreditar" de modo que o fragmento foi tipificado com abordagem por questionamentos na qual foi verificado que há base na ciência; divulgação pela mídia; necessidade de lidar com informações incompletas com conflito de evidências científicas; configuração como problema global; pode envolver questões sobre desenvolvimento sustentável; de valores e de raciocínio ético, no que se refere à em quem acreditar; e necessidade do conhecimento de probabilidade e risco.

- Página 100: na seção de abertura do capítulo 5 (unidade 2) é apresentado um texto jornalístico que mostra a opinião de um cientista sobre a farsa na relação entre a presença de clorofluorcarbonetos (CFCs) e a depleção de ozônio na estratosfera, que motivou a proibição da produção desses compostos. Segundo ele, a razão da proibição foi o fim de pagamento de royalties aos inventores pelo tempo da patente e o interesse em registrar novo produto. Embora o texto não coloque uma pergunta propriamente dita, considerou-se que ele pode motivar uma abordagem pontual de tomada de decisão voltada a Temas Ambientais (escolher em quem acreditar). Além disso, foi possível verificar que a controvérsia proposta possui base na ciência; é frequentemente divulgada pela mídia; lida com informações incompletas com conflito de evidências científicas; lida com problemas globais; pode envolver questões sobre desenvolvimento sustentável; envolve valores de raciocínio ético, no que se refere à em quem acreditar; e pode requerer conhecimento de probabilidade e risco.

- Página 131: no encerramento da Unidade 2 é colocado novamente um texto controverso sobre a tomada de decisão acerca de quem acreditar em relação à poluição por CFCs, ligado a Temas Ambientais. O texto traz a abordagem 
de ASC por meio de questionamentos para concluir as discussões iniciadas na página 100 sobre o tema. Dessa forma, também foi possível verificar que a controvérsia proposta possui base na ciência; é frequentemente divulgada pela mídia; lida com informações incompletas com conflito de evidências científicas; lida com problemas globais; pode envolver questões sobre desenvolvimento sustentável; envolve valores de raciocínio ético, no que se refere à em quem acreditar; e pode requerer conhecimento de probabilidade e risco.

- Página 239: na seção de encerramento da unidade 4 são feitos questionamentos acerca das informações passadas na mídia sobre produtos químicos que podem ser deliberadamente manipuladas. O questionamento principal "como filtrar a verdade em meio a tantas notificas manipuladas" pode ser classificada como uma tomada de decisão que envolve certo embasamento científico; a formação de opiniões e realização de escolhas; ocorrência frequentemente divulgada pela mídia, em especial em comerciais de produtos; e a necessidade de lidar com informações (intencionalmente) incompletas. Diante disso, classificou-se a unidade de contexto como possibilidade de abordar ASC por meio de questionamentos acerca de Temas Ambientais.

- Página 285: na seção de encerramento da unidade 5 é novamente trazida a questão de confiabilidade de informações, dessa vez relacionadas ao tema de desenvolvimento sustentável. Por isso, a unidade de codificação envolve certo embasamento científico; a formação de opiniões e realização de escolhas; ocorrência frequentemente divulgada pela mídia, em especial em comerciais de produtos; a necessidade de lidar com informações (intencionalmente) incompletas; e relação com o desenvolvimento sustentável. Diante disso, classificou-se a unidade de contexto como possibilidade de abordar ASC por meio de questionamentos considerando Temas Ambientais.

Com base nos dados de categorização das seções, é possível afirmar que o livro 1 (REIS, 2016) apresenta elementos relacionados a ASC, em sua maioria abordados por questionamentos que não são tratados no livro de forma completa, ou seja, o livro, sozinho, não contém todos os elementos necessários para um discussão, que deverão ser trazidos de outros meios. Foi observado um caso de abordagem temática no início da unidade 1, mas a discussão de ASC não foi estimulada do conjunto do livro. Infere-se que um professor adotante dessa obra não tenha elementos suficientes para abordar ASC se utilizar somente o livro como fonte de informação. 
Quadro 3: Análise aprofundada do Livro 1

\begin{tabular}{|c|c|c|}
\hline \multirow[t]{2}{*}{$\begin{array}{l}\text { Estrutura do } \\
\text { conteúdo }\end{array}$} & \multicolumn{2}{|c|}{$\begin{array}{l}\text { Todas as unidades estão relacionadas ao tema global de Temas Ambientais. } \\
\text { Apenas a Unidade } 3 \text { não apresentou a abordagem de ASC. A Unidade } 1 \text { apre- } \\
\text { sentou a maior frequência de elementos com características ASC. Em geral, } \\
\text { a abordagem é pontual ou por questionamentos, mas o conteúdo do livro não } \\
\text { baseia a discussão das questões. }\end{array}$} \\
\hline & \multicolumn{2}{|c|}{$\begin{array}{l}\text { Todos os capítulos têm seção de abertura com texto jornalístico facilmente } \\
\text { relacionado com o tema global Temas Ambientais (vide: Foi notícia, abaixo) }\end{array}$} \\
\hline $\begin{array}{l}\text { Características do } \\
\text { texto de conteúdo }\end{array}$ & \multicolumn{2}{|c|}{$\begin{array}{l}\text { O conteúdo é apresentado em texto corrido com alguns questionamentos so- } \\
\text { bre o cotidiano, mas não apesenta ASC }\end{array}$} \\
\hline \multirow{4}{*}{$\begin{array}{l}\text { Descrição dos } \\
\text { boxes }\end{array}$} & $\begin{array}{l}\text { Foi notícia: Todos os capítulos têm se- } \\
\text { ção de abertura com texto jornalístico } \\
\text { facilmente relacionado com o tema } \\
\text { global Temas Ambientais. Apenas os } \\
\text { caps. } 3 \text { e } 5 \text { apresentam ASC, o qual é } \\
\text { inserido de forma pontual }\end{array}$ & $\begin{array}{l}\text { De onde vem... Para onde vai?: apre- } \\
\text { sentação de matérias-primas, proces- } \\
\text { sos de obtenção e uso de substân- } \\
\text { cias. Em geral não apresentam ASC } \\
\text { (exceto cap. 2) }\end{array}$ \\
\hline & $\begin{array}{l}\text { Retomando a notícia: apesar de liga- } \\
\text { das aos Temas Ambientais, não apre- } \\
\text { sentam ASC, exceto nos caps. } 5 \text { e } 11, \\
\text { que foram feitas por meio de questio- } \\
\text { namentos }\end{array}$ & $\begin{array}{l}\text { Saúde e sociedade: relação da Quí- } \\
\text { mica com a saúde e sociedade, mas } \\
\text { não são apresentadas questões con- } \\
\text { troversas }\end{array}$ \\
\hline & $\begin{array}{l}\text { Experimentos: Não apresentam cará- } \\
\text { ter de investigação, nem questiona- } \\
\text { mentos ASC }\end{array}$ & $\begin{array}{l}\text { Compreendendo o Mundo: em quase } \\
\text { todas as unidades (exceto a } 3 \text { ) foram } \\
\text { trazidas questões ao final com ASC, } \\
\text { mas que não podem ser discutidas em } \\
\text { sua totalidade com o conteúdo do livro }\end{array}$ \\
\hline & $\begin{array}{l}\text { Cotidiano do químico: Descreve o tra- } \\
\text { balho do químico e/ou técnicas labo- } \\
\text { ratoriais e não apresenta ASC }\end{array}$ & $\begin{array}{l}\text { Curiosidade: Apresenta temas para } \\
\text { motivar o interesse, mas não apresenta } \\
\text { questões controversas (exceto cap. 3) }\end{array}$ \\
\hline Exerc & \multicolumn{2}{|c|}{$\begin{array}{l}\text { Somente de exames vestibulares / Enem, apresentados em vários momentos } \\
\text { do capítulo. Consideramos não ASC }\end{array}$} \\
\hline
\end{tabular}

Fonte: Reis (2016)

\section{Livro 2: Mortimer e Machado (2017)}

O quadro 4 sumariza as principais características das seções do livro 2 frente aos critérios de categorização, baseado nos exemplos de fragmentos com características ASC retirados do material:

- Página 95: em um dos boxes de reflexão (capítulo 4), os alunos são convidados a analisar as escolhas feitas por uma empresa de papel para implementar medidas de produção mais limpa $(\mathrm{P}+\mathrm{L})$. No exercício, os alunos devem justificar as escolhas feitas pela empresa considerando fatores econômicos, 
ambientais e sociais, caracterizando uma controvérsia. Foi possível relacionar à atividade elementos que envolvam embasamento científico; a formação de opiniões e tomada de decisão; divulgação frequente na mídia; e discussões acerca do desenvolvimento sustentável. Dessa forma, a unidade de contexto foi considerada como tendo potencial para abordagem ASC pontual.

- Página 100 e 250: Nessas páginas são propostas atividades diferenciadas, que poderiam promover discussões de ASC, caso a condução da atividade promovesse momentos de discussão. Acredita-se que da maneira como está posta, poderia ser somente um exercício de reflexão do grupo.

Finalmente, após as análises apresentadas, foi possível concluir que a obra apresenta poucos elementos com potencial de abordagem de ASC e que a obra não traz os elementos necessários para as discussões, apenas propondo as atividades. O livro apresenta abordagem fortemente marcada pelo estudo centrado no conceito científico, não explorando em profundidade questões concernentes aos ASC.

Quadro 4: Análise aprofundada do Livro 2

\begin{tabular}{|c|c|c|}
\hline \multirow{2}{*}{$\begin{array}{l}\text { Estrutura do } \\
\text { conteúdo }\end{array}$} & \multicolumn{2}{|c|}{$\begin{array}{l}\text { A divisão dos capítulos é feita baseada fortemente nos conceitos científicos } \\
\text { abordados, não apresentado laços estreitos com temas globais (com exceção } \\
\text { dos caps. } 3 \text { e 4). }\end{array}$} \\
\hline & \multicolumn{2}{|c|}{$\begin{array}{l}\text { Os principais temas foram saúde e população e temas ambientais, mas ape- } \\
\text { nas no capítulo } 4 \text { foi possível observar a presença de elementos que apoiam } \\
\text { a discussão de ASC }\end{array}$} \\
\hline $\begin{array}{l}\text { Características do } \\
\text { texto de conteúdo }\end{array}$ & \multicolumn{2}{|c|}{$\begin{array}{l}\text { O conteúdo é apresentado em formato de texto corrido, complementado pelas } \\
\text { informações dos boxes, há pouquíssimos questionamentos, nunca controver- } \\
\text { sos }\end{array}$} \\
\hline \multirow{5}{*}{$\begin{array}{l}\text { Descrição dos } \\
\text { boxes }\end{array}$} & Além da Química: não aborda ASC & Exercícios: não aborda ASC \\
\hline & $\begin{array}{l}\text { Um pouco de História: não aborda } \\
\text { ASC }\end{array}$ & Questões de exames: não aborda ASC \\
\hline & Cálculos: não aborda ASC & $\begin{array}{l}\text { Reflexão: dificilmente trazem questões } \\
\text { ASC }\end{array}$ \\
\hline & $\begin{array}{l}\text { Na internet: (não foi citado, por não } \\
\text { oferecer questões) }\end{array}$ & $\begin{array}{l}\text { Questões preliminares: não trazem } \\
\text { questões ASC }\end{array}$ \\
\hline & $\begin{array}{l}\text { Investigação: dificilmente trazem } \\
\text { questões ASC }\end{array}$ & $\begin{array}{l}\text { Projeto: dificilmente trazem questões } \\
\text { ASC }\end{array}$ \\
\hline
\end{tabular}

Fonte: Mortimer e Machado (2017) 
Livro 3: Santos e Mól (2016)

O quadro 5 sumariza as principais características das seções do livro 3 frente aos critérios de categorização, baseado nos exemplos de fragmentos com características de ASC retirados do material. A partir da análise desse livro, sentiu-se necessidade de se colocar outro tema de relevância social que não foi descrito em Santos (2002): natureza da ciência. Os autores dessa obra se preocuparam, em vários momentos, em mostrar a ciência como a construção humana e o processo de construção de conhecimento, sendo esse um tema de relevância no contexto do ensino de Ciências. Além disso, sentiu-se a necessidade de incluir no rol de temas globais os Temas Sociais, que não estão diretamente relacionados com a economia. Dessa forma, esses elementos figuram nas análises em conjunto com os temas globais.

Outro elemento diferenciado trazido pela obra refere-se à tipificação da controvérsia, que foi baseada em $\mathrm{O}$ autor (2015). Nesse livro foram propostas atividades de debate que foram tipificadas como um tipo a parte de controvérsia, por não envolver a tomada de decisão, mas envolver a apresentação e a reflexão sobre pontos de vista. A outra atividade proposta foi a prática social, na qual os alunos devem mobilizar outras pessoas por meio de campanhas, entrevistas e outras atividades.

- Texto de conteúdo do capítulo 1, em especial na página 18: é feita uma discussão sobre o papel da Química na sociedade e a natureza do conhecimento científico sob o contexto do consumismo. No tópico 1 é abordado o tema do consumismo, trazendo elementos como desperdício e consumo sustentável. No tópico 3 é discutida a relação da Química com a Sociedade e a Tecnologia. São postas questões sobre o papel da ciência, sua neutralidade e os interesses envolvidos na construção do conhecimento. Entende-se que esse tema é controverso na medida em que instiga o aluno a confrontar pontos de vista e tomar partido sobre a natureza da ciência. É possível identificar a relação com a ciência; e a formação de opiniões baseada em valores; que permite classificar a unidade de contexto como potencial promotora de ASC de forma temática, pois envolve todo o capítulo.

- Página 10: no box "participação cidadã" (capítulo 1) são feitas uma série de questionamentos sobre aspectos éticos, sociais e econômicos do consumismo. Os temas abordados referem-se consumismo (Questões econômicas) e descarte de resíduos (Temas ambientais). A controvérsia é posta em pontos como: "O consumo é fundamental para o desenvolvimento econômico de 
um país?" e comentários sobre a influência da cultura do "ser" e do "ter" no cotidiano. As controvérsias são a necessidade de formação de opinião e a tomada de decisão; a recorrência do tema na mídia; a ocorrência global do tema; a valoração de critérios de custo benefício; a possibilidade de discussão sobre desenvolvimento sustentável; e a movimentação de valores. Sendo assim, esse fragmento foi classificado como potencial promotor de ASC por meio de questionamentos.

- Página 19: na seção de exercícios do capítulo 1, a questão 15 "O desenvolvimento da Química permitiu o aumento da expectativa e da qualidade de vida das pessoas. Por que então dois terços da população do planeta estão sujeitos às doenças, cujo controle já é domínio da ciência, moram em residências sem as condições mínimas de habitação e não tem acesso à alimentação mínima exigida pelos padrões de saúde?" promove uma reflexão sobre o papel da Química no desenvolvimento social. Acredita-se que tenha o potencial de promover a discussão de ASC se o professor estimular a discussão na hora da resolução. A controvérsia mobiliza questões de formação de opinião; de problemas que aparecem frequentemente na mídia, em espacial sobre regiões com baixo desenvolvimento; sendo problemas globais. Tal reflexão visa a justificativa de uma situação cotidiana que será baseada em valores. Por isso, esse fragmento foi classificado como potencial promotor de discussão ASC por meio de questionamento.

- Página 37: na seção de encerramento do capítulo 1 (box "revisão para a prova"), algumas questões foram classificadas como potenciais promotoras da discussão de ASC. São elas, a questão 1, que discute sobre o desperdício, fazendo com que os alunos avaliem proposições sobre consumismo; a questão 2 que relaciona consumo, consumismo e desperdício com a avaliação de proposições; e as questões 7 e 8 que relacionam desenvolvimento tecnológico e social. Dessa forma, essa parte do texto foi considerada potencial promotora de discussões de ASC como tomada de decisão das assertivas corretas e incorretas acerca do consumismo e desenvolvimento social (Questões econômicas), sendo que a discussão pode mobilizar questões de formação de opinião; de problemas que aparecem frequentemente na mídia, em espacial sobre regiões com baixo desenvolvimento; sendo problemas globais. 
Tal reflexão visa a justificativa de uma situação cotidiana que será baseada em valores.

- Página 48: em um dos boxes "participação cidadã" no capítulo 2, os alunos são convidados a julgar a opinião ("Julgue a opinião [...] 'a coleta seletiva é um processo trabalhoso que somente beneficia a indústria de reciclagem [...]" e campanhas de coleta seletiva "analise campanhas [...] em relação à coleta de latas para reciclagem, apontando aspectos positivos e negativos e justificando se elas devem continuar [...]". Esses questionamentos, em analogia ao caso anterior, abordam os mesmos critérios de relevância para a discussão controvertida, além de possuir base científica. Dessa forma, esse fragmento foi classificado como potencial promotor de discussão de ASC por meio de questionamentos sobre descarte de resíduos e coleta seletiva (Temas Ambientais).

- Página 77: em outro box "participação cidadã” no capítulo 2, o aluno é estimulado a tomar posição quanto ao melhor sistema para descarte de resíduos em sua cidade, considerando aspectos sociais e econômicos, além a atuação civil. Essa atividade, em analogia ao caso anterior, abordam os mesmos critérios de relevância para a discussão controvertida. Por isso, esse fragmento foi classificado como potencial promotor de discussão de ASC por meio de questionamentos sobre descarte de resíduos e coleta seletiva (Temas Ambientais).

- Página 78: na seção de encerramento do capítulo 2 (box "revisão para a prova") algumas questões foram classificadas como potenciais promotoras da discussão de ASC. A saber, a questão 1 prevê a avaliação assertiva sobre ações de diminuição de produção de resíduos; a 2 sobre impactos e vantagens da reciclagem; e as questões 12 e 14 sobre impactos e vantagens de diferentes meios de destinação de resíduos. Dessa forma, essa parte do texto foi considerada potencial promotora de discussões de ASC como tomada de decisão das assertivas corretas e incorretas acerca do consumismo e desenvolvimento social (Questões econômicas) sendo que a discussão pode mobilizar questões de formação de opinião; de problemas que aparecem frequentemente na mídia, em espacial sobre regiões com baixo desenvolvimento; sendo problemas globais. Tal reflexão visa a justificativa de uma situação cotidiana que será baseada em valores. 
- Página 137: no box "tomada de decisão" (cap. 3), os alunos são motivados a se posicionar a favor ou contra o uso de organismos geneticamente modificados considerando valores éticos e aspectos sociais e ambientais. A atividade requisita a formação de opinião, relacionada com o conhecimento científico estudado sobre um tema amplamente divulgado, envolvendo análise de custo benefício, questões de desenvolvimento sustentável e a articulação de valores éticos. Por isso o fragmento foi classificado como potencial promotor de discussão de ASC pontual.

- Página 137: no box "ação e cidadania" (cap. 3), os alunos são convidados a debater o tema anterior do ponto de vista de diferentes atores sociais (como cientistas, políticos, trabalhadores, religiosos). Sendo assim, considerou-se que essa unidade de contexto apresenta as mesmas características e classificação da anterior.

- Página 157: no box "participação cidadã" (cap. 4), os alunos são estimulados a discutir sobre o tema diversidade. Tal ponto envolve elementos de embasamento científico; formação de opinião sobre problemas frequentas na mídia; que envolvem evidências científicas incompletas; e a mobilização de valores. Esse fragmento foi, então, classificado como potencial promotor de ASC por meio de questionamentos, na forma de debate sobre o tema diversidade (Temas Sociais).

- Página 157: no box "ação e cidadania" (cap. 4), os alunos são convidados a fazer uma campanha de sensibilização sobre o tema diversidade (Temas Sociais). Sendo assim, esse elemento foi classificado como o anterior, mas com a abordagem do tipo prática social.

- Página 210: no box "participação cidadã" (cap. 5), os alunos são convidados a tomar posição sobre a importância da redução do uso de embalagens em relação a aspetos ambientais e sobre a importância da rotulagem, em especial de produtos químicos de uso cotidiano. Há a tomada de decisão baseada na formação de opinião; fundamentada pelo conhecimento científico; que motivou a classificação do fragmento em um potencial promotor de discussão de ASC por meio de questionamentos.

- Página 219: no box "participação cidadã" (cap. 6), os alunos são convidados a pesquisar sobre as causas de acidentes ligados a incêndios, relacionando responsáveis, medidas de segurança e meios de prevenir. A controvérsia 
refere-se à responsabilização e envolve embasamento científico e mobilização de valores para a formação de opiniões. Por isso, classificou-se o fragmento em um debate por meio de questionamentos sob o tema Saúde e População (riscos à saúde).

Quadro 5: Análise aprofundada do Livro 3

\begin{tabular}{|c|c|c|}
\hline \multirow{2}{*}{$\begin{array}{l}\text { Estrutura do } \\
\text { conteúdo }\end{array}$} & \multicolumn{2}{|c|}{$\begin{array}{l}\text { Os capítulos não têm abordagem temática porque o contexto social não é tra- } \\
\text { balhado de forma contínua }\end{array}$} \\
\hline & \multicolumn{2}{|c|}{$\begin{array}{l}\text { As seções de abertura não permitiam ASC, nos caps. } 1,2 \text { e } 3 \text { houveram ques- } \\
\text { tões que poderiam levar a discussão ASC (por questionamento) }\end{array}$} \\
\hline $\begin{array}{l}\text { Características do } \\
\text { texto de conteúdo }\end{array}$ & \multicolumn{2}{|c|}{$\begin{array}{l}\text { Com exceção do cap. } 7 \text {, o texto do capítulo continha ao menos um item que } \\
\text { buscava relacionar o conteúdo com um temos social e permite discussões de } \\
\text { ASC sem colocar as controversas no texto }\end{array}$} \\
\hline \multirow{5}{*}{$\begin{array}{l}\text { Descrição dos } \\
\text { boxes }\end{array}$} & Pare e pense: não aborda ASC & $\begin{array}{l}\text { Construção do conhecimento: não } \\
\text { aborda ASC }\end{array}$ \\
\hline & Atividade experimental: não aborda ASC & História da ciência: não aborda ASC \\
\hline & $\begin{array}{l}\text { Revisão para a prova: caps. } 1,2 \text { e } 3 \text { com } \\
\text { questões que podem levar a discussões } \\
\text { de ASC }\end{array}$ & Atitude sustentável: não aborda ASC \\
\hline & $\begin{array}{l}\text { Participação cidadã: sempre aborda } \\
\text { ASC, mas não está presente em todos } \\
\text { os capítulos }\end{array}$ & $\begin{array}{l}\text { Ação e cidadania: nem sempre } \\
\text { aborda ASC. }\end{array}$ \\
\hline & $\begin{array}{l}\text { Tomada de decisão: sempre aborda } \\
\text { ASC, mas não está presente em todos } \\
\text { os capítulos }\end{array}$ & $\begin{array}{l}\text { Exercícios: cap. } 1 \text { teve possibilidade } \\
\text { de ASC }\end{array}$ \\
\hline
\end{tabular}

Fonte: autoria própria, a partir de Santos e Mól (2016)

Considerando todos os elementos supracitados, pode-se afirmar que a obra se propõe a discutir os ASC e é possível observar a presença de tomadas de decisão, de debates e de justificativas de maneira pontual e por questionamentos, em boxes separados, e um caso de abordagem temática mais abrangente no primeiro capítulo. O texto de conteúdo traz tópicos de contextualização social que poderiam suscitar a discussão de ASC, mas não são apresentadas controvérsias no texto (à exceção do capítulo 1). Em alguns casos, as atividades poderão possibilitar discussões de ASC ou apenas informações, a depender da condução do professor. 


\section{Livro 4: Lisboa (2016)}

O quadro 6 sumariza as principais características das seções do livro 4 frente aos critérios de categorização, baseado nos exemplos de fragmentos com características de ASC retirados do material. Nessa obra também foi sentida a necessidade de classificar um fragmento com o tema Temas Sociais, enriquecendo a gama de possibilidades de tipos de contexto.

- Página 69: no box "ciência, tecnologia e sociedade" (capítulo 4, unidade 1) é apresentado um texto sobre a produção de um tipo de plástico biodegradável e sua relação com o ambiente. $\mathrm{O}$ questionamento 2 dessa atividade pede para que os alunos se posicionem quanto à seguinte questão "a diferença de tempo de degradação no ambiente entre plásticos sintéticos e biodegradáveis justifica o investimento nesses novos produtos? Por quê?", incentivando que os alunos tomem decisões baseadas na formação de opiniões; pautas no conhecimento científico; que se relacionam a avaliações de custo-benefício; e ao desenvolvimento sustentável. Sendo assim, a unidade de contexto foi classificada como sendo potencialmente promotora da discussão de ASC por meio de questionamentos sobre Temas Ambientais (Descarte de Resíduos) e Questões econômicas (responsabilidade do consumidor).

- Página 97: em analogia ao caso anterior, no box "ciência, tecnologia e sociedade" (capítulo 6, unidade 2) é apresentado um texto sobre a descoberta da radioatividade. $\mathrm{O}$ questionamento 3 dessa atividade pede para que os alunos se posicionem quanto à seguinte questão "a radioatividade é benéfica ou não ao ser humano?" incentivando que os alunos tomem decisões baseadas na formação de opiniões; pautadas no conhecimento científico; que se relacionam a avaliações de custo-benefício. Dessa forma, a unidade de contexto foi classificada como sendo potencialmente promotora da discussão de ASC por meio de questionamentos sobre Saúde e População (Usos e riscos da radioatividade).

- Página 103: no box "química tem história" (capítulo 6, unidade 2) é contada a história da tabela periódica e o fato de o nome de Ida Eva não ser ignorado nas obras científicas. No questionamento da atividade o aluno é levado a tomar posição sobre recorrência da desigualdade de gênero no meio científico. Sendo assim, o fragmento foi classificado como potencialmente promotor de discussões de ASC por meio de questionamento sobre 
Temas Sociais (Desigualdade de Gênero) envolvendo a formação de opinião; baseada em conhecimento científico; e valores éticos; sobre um problema frequentemente divulgado.

Quadro 6: Análise aprofundada do Livro 4

\begin{tabular}{|c|c|c|}
\hline \multirow{2}{*}{$\begin{array}{l}\text { Estrutura do } \\
\text { conteúdo }\end{array}$} & \multicolumn{2}{|c|}{$\begin{array}{l}\text { As unidades são divididas de acordo com o conteúdo químico. As seções de } \\
\text { abertura não trazem elementos que permitem empregar ASC }\end{array}$} \\
\hline & \multicolumn{2}{|c|}{$\begin{array}{l}\text { Os capítulos são organizados de acordo com o conteúdo químico e não for- } \\
\text { nece elementos para discussão de ASC. Com exceção de } 3 \text { atividades nos } \\
\text { caps. } 1,4 \text { e } 5\end{array}$} \\
\hline $\begin{array}{l}\text { Características do } \\
\text { texto de conteúdo }\end{array}$ & \multicolumn{2}{|c|}{$\begin{array}{l}\text { O texto de conteúdo não apresenta questionamentos que levem à discussão } \\
\text { de ASC, apenas pergunta para averiguar o conhecimento prévio dos alunos }\end{array}$} \\
\hline \multirow{5}{*}{$\begin{array}{l}\text { Descrição dos } \\
\text { boxes }\end{array}$} & Saiba mais: não aborda ASC & $\begin{array}{l}\text { Química tem história: não aborda ASC } \\
\text { (exceto cap. 5) }\end{array}$ \\
\hline & Você se lembra: não aborda ASC & $\begin{array}{l}\text { Ação e cidadania: apresentam contextua- } \\
\text { lização, sem abordar ASC }\end{array}$ \\
\hline & $\begin{array}{l}\text { Química e...: apresentam contex- } \\
\text { tualização, não aborda ASC ASC }\end{array}$ & Atividades: não aborda ASC ASC \\
\hline & $\begin{array}{l}\text { Enem e Vestibular: não aborda } \\
\text { ASC ASC }\end{array}$ & $\begin{array}{l}\text { Ciência, Tecnologia e Sociedade: apre- } \\
\text { senta contextualização e nos caps. } 1 \text { e } 4 \\
\text { podem levar à discussão de ASC }\end{array}$ \\
\hline & $\begin{array}{l}\text { Atividade experimental: não abor- } \\
\text { da ASC ASC }\end{array}$ & $\begin{array}{l}\text { Projeto: não aborda ASC ASC, embora pos- } \\
\text { sam ser considerados contextualizados. }\end{array}$ \\
\hline
\end{tabular}

Fonte: autoria própria, a partir de Lisboa (2016)

Com base nos elementos apresentados acima, conclui-se que o livro não apresenta subsídios para a discussão de ASC, não traz elementos controversos e poucas vezes aborda temas que podem ser, se conduzidos pelo professor, discutidos de forma sociocientífica, trazendo apenas três situações em que as atividades poderia levar à discussões de ASC.

Livro 5: Ciscato et al. (2016)

O quadro 7 sumariza as principais características das seções do livro 5 frente aos critérios de categorização, baseado nos exemplos de fragmentos com características de ASC retirados do material. 
- Página 35: na seção de encerramento do capítulo 1, mais especificamente no box "atividade em grupo", os alunos são convidados a elencar métodos de conservação de alimentos e como minimizar o desperdício. A controvérsia se forma em todo da tomada de decisão quanto a quais produtos são melhores: in natura ou industrializados. Dessa forma, esse box foi considerado uma atividade que motiva a formação de opinião; baseada em conhecimento científico; e avaliação de custo-benefício; sendo potencial promotora de discussão pontual de ASC sobre o tema Alimentos e Fome (conservação e desperdício de alimentos).

- Página 77: em analogia ao caso anterior, na seção de encerramento do capítulo 2, mais especificamente no box "atividade em grupo", os alunos são estimulados a se posicionar sobre a influência da produção de biocombustível na disponibilidade de alimentos. Sendo assim, esse fragmento foi considerado uma atividade que motiva a formação de opinião; baseada em conhecimento científico; e avaliação de custo-benefício; em relação ao desenvolvimento sustentável; sendo potencial promotora de discussão pontual de ASC sobre o tema Alimentos e Fome e Questões econômicas (produção de biocombustível e a crise de alimentos).

- Página 185: na seção de encerramento do capítulo 4 (atividade em grupo) os alunos são divididos em dois grupos para que sejam confrontadas as teorias que explicam o aquecimento global. Ao final, os alunos deverão tomar uma decisão ao escolher a teoria que os representa acerca desse tema ambiental. É possível entender que os alunos deverão formar opinião; com embasamento científico; sobre um tema de abrangência global; frequentemente exposto na mídia; que envolve dados inacabados e conflito de teoria. Por isso, essa unidade de contexto foi classificada como potencial promotora de ASC, com abordagem pontual. 
Quadro 7: Análise aprofundada do Livro 5

\begin{tabular}{|c|c|c|}
\hline \multirow[t]{2}{*}{$\begin{array}{l}\text { Estrutura do } \\
\text { conteúdo }\end{array}$} & \multicolumn{2}{|c|}{$\begin{array}{l}\text { O livro se organiza por temas de contextualização, a seção de abertura da } \\
\text { unidade é bastante contextualizada, mas nunca controversa. Os trabalhos em } \\
\text { grupo são mais passiveis de ASC }\end{array}$} \\
\hline & \multicolumn{2}{|c|}{ Os temas são organizados por conteúdos que não permitem discussões de ASC } \\
\hline $\begin{array}{l}\text { Características do } \\
\text { texto de conteúdo }\end{array}$ & \multicolumn{2}{|c|}{$\begin{array}{l}\text { O texto de conteúdo não apresenta questionamentos que levem à discussão } \\
\text { de ASC, apenas pergunta para averiguar o conhecimento prévio dos alunos }\end{array}$} \\
\hline \multirow{3}{*}{$\begin{array}{l}\text { Descrição dos } \\
\text { boxes }\end{array}$} & Box genérico: não aborda ASC & Glossário: não aborda ASC \\
\hline & $\begin{array}{l}\text { Atividade prática: não aborda } \\
\text { ASC }\end{array}$ & $\begin{array}{l}\text { Questões para fechamento do tema: não } \\
\text { aborda ASC }\end{array}$ \\
\hline & $\begin{array}{l}\text { Exercícios finais: não aborda } \\
\text { ASC }\end{array}$ & $\begin{array}{l}\text { Atividades em grupo: sempre contextualiza- } \\
\text { das, mas nos caps. } 1,2 \text { e } 4 \text { apresentam pos- } \\
\text { sibilidades de discussão de ASC claras, nos } \\
\text { outros apenas informativo }\end{array}$ \\
\hline
\end{tabular}

Fonte: autoria própria, a partir de Ciscato et al. (2016)

Diante dos apontamentos elencados, entende-se que apesar do livro ser organizado por temas, as seções de abertura e encerramento dos capítulos serem contextualizadas, os momentos que teriam maior potencial de ASC (caps. 1, 2 e 4) permitem apenas abordagem pontual, ou seja, sem recorrência durante o capítulo de modo que o conteúdo em si continua desconectado do contexto, essencial para a controvérsia sociocientífica.

\section{Livro 6: Antunes e Novais (2016)}

O quadro 8 sumariza as principais características das seções do livro 6 frente aos critérios de categorização, baseado nos exemplos de fragmentos com características de ASC retirados do material. Nessa obra também foi possível encontrar o tema Natureza da Ciência em relação, por exemplo, à percepção da ciência e do conhecimento científico pelas pessoas. Outro ponto interessante na classificação foi a presença de abordagem do tipo debate.

- Página 13: Na abertura do capítulo 1, os alunos têm textos que visam a discussão da percepção da ciência pela comunidade e a proposta é que os alunos decidam se as pessoas com quem eles convivem têm uma visão positiva e negativa da ciência. Sendo assim, esse fragmento foi categorizado como potencial promotor pontual de discussão de ASC por motivar a formação de opinião; baseadas no conhecimento científico; acerca do tema Natureza da Ciência; 
- Página 17: no box "conexões" (capítulo 1, unidade 1) é feita uma atividade que motiva os alunos a tomarem posição quanto ao papel da ciência no desenvolvimento humano em função de usos benéficos e negativos trazidos pelo desenvolvimento científico (natureza da ciência). É possível relacionar a formação de opinião; embasados no conhecimento científico; e em valores; de importância, justificando a classificação como possível promotor pontual de discussão de ASC.

- Página 109: no box "conexões" (capítulo 5, unidade 2) é feito um debate sobre aspectos sociais, econômicos e ambientais envolvidos na exploração de minérios (Questões econômicas), durante o qual os alunos eram motivados a formar opiniões; baseadas em critérios científicos; valores; e análise de custo-benefício; relacionados, também, ao desenvolvimento sustentável; que motivou a classificação dessa atividade em possível articuladora de discussão de ASC de forma pontual.

- Página 167: na abertura do capítulo 8 (unidade 3) há uma atividade que estimula o debate (abordagem pontual de ASC), da relação entre o crescimento populacional e a distribuição de alimentos (Saúde e População) que envolve a formação de opinião; embasada cientificamente; de um problema global (CR 5).

Quadro 8: Análise aprofundada do Livro 6

\begin{tabular}{|l|l|l|}
\hline \multirow{4}{*}{$\begin{array}{l}\text { Estrutura do } \\
\text { conteúdo }\end{array}$} & $\begin{array}{l}\text { A divisão dos capítulos é feita baseada fortemente nos conceitos científicos } \\
\text { abordados, não apresentando laços estreitos com temas globais }\end{array}$ \\
\cline { 2 - 3 } & $\begin{array}{l}\text { Os principais temas foram saúde e população e temas ambientais. A possibilida- } \\
\text { de de ASC foi encontrada nos caps. 1, 5, 8 e 10. }\end{array}$ \\
\hline $\begin{array}{l}\text { Características } \\
\text { do texto de } \\
\text { conteúdo }\end{array}$ & $\begin{array}{l}\text { O conteúdo é apresentado em formato de texto corrido complementado pelas } \\
\text { informações dos boxes, há questionamentos, nunca controversos }\end{array}$ \\
\hline \multirow{5}{*}{$\begin{array}{l}\text { Descrição dos } \\
\text { boxes }\end{array}$} & $\begin{array}{l}\text { Para situá-lo: não aborda ASC } \\
\text { questões voltadas aos conceitos químicos } \\
\text { exclusivamente }\end{array}$ & $\begin{array}{l}\text { Atividades: questões que não } \\
\text { perguntas, não aborda ASC }\end{array}$ \\
\cline { 2 - 3 } & Viagem no tempo: não aborda ASC & $\begin{array}{l}\text { Testando seus conhecimentos: } \\
\text { não aborda ASC }\end{array}$ \\
\cline { 2 - 3 } & Conexões: possibilidades de ASC em 1, 5 e 8 & $\begin{array}{l}\text { Regatando o que foi visto: não } \\
\text { aborda ASC }\end{array}$ \\
\cline { 2 - 3 } & Atividade de encerramento do capítulo: sem ASC \\
\hline
\end{tabular}

Fonte: autoria própria, a partir de Antunes e Novais (2016) 
- Página 181: no box "conexões" (capítulo 8, unidade 3), os alunos são estimulados a debater (abordagem pontual de ASC) sobre o acesso à informação das pessoas a componentes tóxicos de produtos e ao comércio de produtos potencialmente tóxicos (Saúde e população). Para tal, envolve a formação de opinião; baseada em conhecimento científico; e análise de curso benefício.

- Página 207: na abertura do capítulo 10 (unidade 3) é proposto um debate sobre a proibição ou não da fabricação de alimentos em tachos de cobre devido ao risco de contaminação e a importância socioeconômica dessa prática. Dessa forma, o fragmento pode ser classificado como uma prática potencialmente sociocientífica de debate (abordagem pontual), que mobiliza a formação de opiniões; embasados na ciência; na avaliação de custo benefício; e da valores de acordo com a visão.

Com base nas indicações feitas, é possível dizer que a obra apresenta poucos elementos relacionados a ASC, em sua maioria pontuais (debates), que não são tratados no livro de forma completa, pois é requerida etapa de pesquisa externa.

\section{Comparação entre as obras}

A partir das análises aprofundadas das obras foi possível perceber que todas elas apresentam ao menos um fragmento que possui características que possibilitam abordagem de ASC em sala de aula. Em contrapartida, o texto dos livros não apresenta elementos para a discussão das controvérsias presentes nas atividades. Esse ponto indica que as obras sozinhas não trazem todos os subsídios necessários para a discussão de ASC conforme os critérios elencados aqui, cabendo ao professor proporcionar materiais complementares que fomentem o processo de discussão.

Em relação aos temas globais de significação social (MERRYFIELD, 1991 apud SANTOS, 2002), observa-se que os Temas Ambientais aparecem em maior destaque nos livros, indicando a ampla relação entre os conteúdos da Química e conceitos relativos ao meio ambiente. Em menor escala, são verificados temas como Saúde e População e Questões Econômicas, indicando o caráter interdisciplinar da Química. Além disso, em algumas obras foram encontrados exemplos de contextualização que não se enquadravam nos temas propostos por Merryfield (1991 apud SANTOS, 2002): Natureza da Ciência (questões referentes ao caráter conjectural do conheci- 
mento científico e dos aspectos humanos da construção do conhecimento) e Temas Sociais (tema mais amplo que o de Questões Econômicas, tratando questões como qualidade de vida).

Quanto ao tema Natureza da Ciência, entendemos que não tem a característica dos outros temas globais no que se refere a ser uma preocupação da população em geral. Contudo, ao se analisar livros para a aplicação escolar, defendemos que é um tema de contextualização relevante para o processo de ensino e aprendizagem da Química.

Em relação ao tipo de abordagem nas atividades que possibilitam a discussão de ASC (HALMENSCHLAGER; DELIZOICOV, 2017; SANTOS, 2002), a abordagem por questionamentos está presente na maioria dos fragmentos, sendo realizada por meio de perguntas que trazem controvérsias ligadas ao conhecimento químico. Em poucos casos foi observada a análise temática, que é desenvolvida durante todo o capítulo em conjunto com o elemento de contextualização e o conteúdo.

Por fim, em relação ao tipo de controvérsia (STADLER, 2015) foi observado que a maior parte dos fragmentos demanda que os alunos tomem decisões acerca de temas controversos com base nos elementos apresentados e/ou em pesquisas externas. Também foi necessário elencar mais dois tipos controvérsia: debates, no qual era estimulada argumentação frente a um tema; e prática social, quando os alunos deveriam expor os resultados a outros grupos. Isso se justifica pelo fato que, nesses casos, não era necessária a tomada de decisão ou a explicação/justificativa de decisão já tomada, mas argumentação e exposição de ideias próprias em diferentes contextos. Além disso, os dois tipos apresentados neste estudo não foram encontrados no trabalho de Stadler (2015), que analisou avaliações do Exame Nacional do Ensino Médio, nas quais a interação entre os candidatos é vedada.

De base desses resultados, em especial a presença de elementos com potencial para a abordagem de ASC em todas as obras, inferimos que esse tipo de discussão pode ser incluído nos mais diversos tipos de abordagens e não somente naquelas declaradamente sociocientíficas, como o caso do livro 3 (SANTOS; MÓL, 2016).

\section{Considerações finais}

A abordagem de ASC no ensino de Química tem papel importante na promoção da significação no processo de ensino e aprendizagem e de estímulo do protagonis- 
mo dos estudantes no processo de construção do conhecimento. Esse fato decorre da mobilização dos conceitos estudados por meio de controvérsias que os ligam a contextos de interesse e estimulam a argumentação e exposição de ideias. A análise da presença desses aspectos e da forma como são abordados em livros didáticos distribuídos nas escolas públicas é de extrema relevância quando se considera 0 papel importante desse recurso na maior parte das salas de aula, figurando, às vezes, como único recurso didático disponível.

Dessa forma, inferimos que, caso haja a abordagem de ASC nos livros didáticos, é possível que eles sejam discutidos em sala de aula. A partir da análise de conteúdo realizada, foi possível perceber que todas as obras fornecidas apresentam, em menor ou maior grau, atividades que possibilitam a discussão de temas controversos socialmente relevantes, de acordo com os critérios apresentados. Essa constatação é importante para indicar que os ASC são, de fato, relevantes para o ensino de Química.

Este estudo ainda contribuiu para melhorar os trabalhos usados como referencial no que diz respeito aos temas de relevância, ao aumentar o rol de possibilidades a partir dos temas globais apresentados por Merryfield (1991 apud SANTOS, 2002) para materiais de larga escala. E na tipificação da controvérsia apresentada por Stadler (2005), apresentando mais possibilidades de atividades envolvendo a abordagem de ASC. Com base nas análises aqui realizadas, inferimos que há potencial para a abordagem de ASC nas salas da aula de Química em torno de diversos temas e com tipos variados de atividades. $\mathrm{O}$ que necessita ser feito, defendemos, é a popularização desta abordagem entre os professores da Educação Básica.

Trabalhos posteriores na área, além de estender a análise para os livros destinados à segunda e terceira séries do Ensino Médio, podem possibilitar melhores discussões do papel desta abordagem na formação do cidadão crítico e autônomo por meio do livro didático. Além disso, pode-se propor a avaliação da percepção dos professores da Educação Básica acerca da relevância e aplicabilidade de ASC em sala de aula. 


\section{Analysis of socio-scientific issues in chemistry textbooks used in high school}

\section{Abstract}

The investigation for textbook usage is relevant because of the importance of this didactic resource. Most times these are the only instrument for the student's study and teacher support, through the wide distribution promoted around the country by the National Textbook Program (PNLD). Among the various conceptions of chemistry teaching, the Socio-scientific Issues (SSI) approach uses contextualization based on socially relevant themes mobilized by the discussion of controversies based on scientific knowledge. Therefore, investigating the presence of SSI in chemistry textbooks can help teachers to use it. The analysis of chemistry books for the first grade of high school distributed by PNLD was the center of this research. The method was the content analysis based on the indicators: global theme, presence of controversy and relevance criteria to classify the texts as potential promoters of socio-scientific discussions. Subsequently, the approach and the controversy were delimited. The large differences found between the works prevented their comparison by the fragment. Thus, we fragmented the works during the categorization, produce a profile and compare them. Although all works have fragments that have the potential to foster socio-scientific discussion, books do not provide all the information for the controversial discussion. In addition, there was a need to increase the amount of context themes and types of approach to cover the examples in the books.

Keywords: Socio-scientific issues; Textbooks, PNLD, Science Teaching.

\section{Referências}

BARDIN, Lawrance. Análise de Conteúdo. Lisboa: Edições 70, 2011.

BRASIL. Lei № 9.394 de 20 de dezembro de 1996. Estabelece as diretrizes e bases da educação nacional, Brasília, 1996.

BRASIL. Base Nacional Comum Curricular. Brasília: MEC, 2017. Disponível em: http://basenacionalcomum.mec.gov.br/images/BNC C_20dez_site.pdf. Acesso em: 22 de dezembro de 2017.

BRASIL. PNLD 2018: apresentação - guia de livros didáticos - ensino médio/ Ministério da Educação - Secretária de Educação Básica - SEB - Fundo Nacional de Desenvolvimento da Educação. Brasília, DF: Ministério da Educação, Secretária de Educação Básica, 2017.

CISCATO, Carlos Alberto Mattoso; et al. Química. São Paulo: Moderna, 2016

DELIZOICOV, Demétrio, ANGOTTI, José André, PERNAMBUCO, Marta Maria. Ensino de Ciências: fundamentos e métodos. São Paulo: Cortez, 2018.

FERNANDES-SOBRINHO, Marcos. Temas sociocientíficos no Enem e no livro didático: limitações e potencialidades para o ensino de Física. Brasília: UnB. Tese de Doutorado em Educação. Universidade de Brasília, 2014. 
FRACALANZA, Hilário. O que sabemos sobre os livros didáticos para o ensino de ciências no Brasil. Campinas: Unicamp. Tese de doutorado em Educação. Faculdade de Educação, Universidade de Campinas, 1992.

GIL, Antônio Carlos. Como elaborar projetos de pesquisa. São Paulo: Atlas, 2010.

HALMENSCHLAGER, Karine Raquiel, DELIZOICOV, Demétrio. Abordagem Temática no Ensino de Ciências: Caracterização de Propostas Destinadas ao Ensino Médio. Alexandria: R. Educ. Ci. Tec., v.10, n. 2, p. 305-330, 2017,

LISBOA, Julio César Foschini. Ser Protagonista - Química. São Paulo: SM, 2016.

MERRYFIELD, Merry Marc. Science-technology-society and global perspectives. Theory into Practice, v. 30, n. 4, p. 288-293, 1991.

MORTIMER, Eduardo Fleury, MACHADO, Andréa Horta. Química. São Paulo: Scipione, 2017.

NETO, Jorge Megid; FRACALANZA, Hilário. O Livro Didático de Ciências: Problemas e Soluções. Ciência \& Educação, v. 9, n. 2, p. 147-157, 2003.

NOVAIS, Vera Lúcia Duarte; ANTUNES, Murilo Tissoni. Vivá: Química. Curitiba: Positivo, 2016.

PÉREZ, Leonardo Fabio Martinez; CARVALHO, Washington Luiz Pacheco. Contribuições e dificuldades da abordagem de questões sociocientíficas na prática de professores de ciências. Educação e Pesquisa, v. 38, n. 3, p. 727-741, 2012.

REIS, Martha. Química. São Paulo: Ática, 2016.

SANTOS, Wildson Luiz Pereira. Aspectos sociocientíficos nas Aulas de Química. Belo Horizonte: UFMG. Tese de Doutorado em Educação. Faculdade de Educação, Universidade Federal de Minas Gerais, 2002.

SANTOS, Wildson Luiz Pereira, MÓL, Gerson. Química Cidadã. São Paulo, AJS, 2016.

SANTOS, Wildson Luiz Pereira, MORTIMER, Eduardo Fleury. Abordagem de Aspectos sociocientíficos nas aulas de Ciências: Possibilidades e Limitações. Investigações no Ensino de Ciências, v. 14, n. 2, p. 191-218, 2009.

STADLER, João Paulo. Análise de aspectos sociocientíficos em questões de Química do Enem: subsídio para a elaboração de material didático para a formação cidadã. Curitiba: UTFPR. Dissertação de Mestrado em Formação Científica, Educacional e Tecnológica, Universidade Tecnológica Federal do Paraná, Curitiba. 